\title{
Frequência de anemia infecciosa equina em equinos nos estados da Paraíba, Rio Grande do Norte e Ceará durante o ano de 2010
}

\section{Frequency of equine infectious anemia in equine in the states of Paraíba, Rio Grande do Norte and Ceará, Northeastern Brazil during 2010}

\author{
Carpejane Ferreira SILVA ${ }^{1}$; Nebson Fernandes PEQUENO ${ }^{2}$; Inácio José CLEMENTINO ${ }^{1}$; Sérgio Santos \\ de AZEVEDO ${ }^{1}$; Aloísio SILVA ${ }^{3}$ \\ ${ }^{1}$ Unidade Acadêmica de Medicina Veterinária do Centro de Saúde e Tecnologia Rural da Universidade Federal de Campina \\ Grande, Patos, PB, Brasil \\ ${ }^{2}$ Laboratório Veterinária Diagnóstico Ltda, Catolé do Rocha, PB, Brasil \\ ${ }^{3}$ Defesa Agropecuária da Paraíba, SEDAP, João Pessoa, PB, Brasil
}

\begin{abstract}
Resumo
A frequência de equinos soro-reagentes para o vírus da Anemia Infecciosa Equina (AIE) foi investigada, durante o ano de 2010, em 5615 animais originários de 209 municípios de três estados do nordeste do Brasil: Paraíba, Rio Grande do Norte e Ceará. Os soros foram examinados com o emprego do teste de imunodifusão em gel de ágar (IDGA) produzido com o antígeno p26. Dos 5615 animais examinados, 151 (2,69\%) foram soropositivos. As proporções de animais reatores positivos por estado foram: Paraíba (2,86\%), Rio Grande do Norte (1,29\%) e Ceará $(3,10 \%)$. Tomando-se por base a menor proporção de resultados positivos encontrada no estado do Rio Grande do Norte, o estado da Paraíba apresentou uma odds ratio de 2,64 (IC 95\% = 1,33-5,36; $\mathrm{p}=0,004$ ) e o Ceará de 2,87 (IC 95\% = 1,48-5,71; $\mathrm{p}=0,001)$. Na Paraíba houve o registro de animais soropositivos em todos os meses do ano, com frequência mínima $(0,58 \%)$ em julho e máxima (5,82\%) em junho; no Rio Grande do Norte de março a maio e de julho a novembro, com variação de $0 \% \mathrm{em}$ janeiro, fevereiro, junho e dezembro a 3,61\% em maio; e no Ceará em todos os meses com frequência mínima $(1,10 \%)$ em agosto e máxima $(7,29 \%)$ no mês de dezembro.
\end{abstract}

Palavras-chave: Retrovírus. Equídeos. Epidemiologia. Nordeste do Brasil.

\begin{abstract}
During the year of 2010 the frequency of equines sero-reactants to the Infectious Anemia vírus (EIA) was investigated in 5,615 animals originated from 209 counties of three northeastern brazilian states: Paraíba, Rio Grande do Norte and Ceará. The serum samples were examined by an agar gel immunodiffusion test (AGID) produced with p26 antigen. Of the 5,615 animals examined 151 (2.69\%) were seropositive to EIA. The proportion of seroreactant animals per state were: Paraíba (2.86\%), Rio Grande do Norte (1.29\%) and Ceará (3.10\%). Paraíba presented an odds ratio of 2.64 (95\% $\mathrm{CI}=1.33-5.36 ; \mathrm{p}=0.004)$, while Ceará had an odds ratio of $2.87(95 \% \mathrm{CI}=1.48-5.71 ; \mathrm{p}=0.001)$ both of them compared with Rio Grande do Norte. Paraíba had seropositive animals in all months of the year, with frequency ranging from $0.58 \%$ in July to $5.82 \%$ in June; in Rio Grande do Norte from March to May and from July to November ranging from $0 \%$ in January, February, June and December to $3.61 \%$ in May; and in Ceará in all months ranging from $1.10 \%$ in August to $7.29 \%$ in December.
\end{abstract}

Keywords: Retrovirus. Equine.Epidemiology. Northeastern Brazil.

\section{Introdução}

Da população de equídeos do Brasil, estimada em 5.947.073 cabeças, 109.286 estão na Paraíba, 259.884 no Ceará e 67.647 no Rio Grande do Norte ${ }^{1}$. Na região nordeste do Brasil os equídeos são criados para trabalho, lazer e, principalmente, para esporte, onde as vaquejadas são a sua principal utilização. Os eventos hípicos propiciam a aglomeração de equídeos 
provenientes de diferentes regiões e nessas ocasiões os animais podem ser expostos a diversos agentes de doenças, dentre os quais se destaca o vírus da Anemia Infecciosa Equina, que é endêmico nos estados do nordeste do Brasil.

A Anemia Infecciosa Equina (AIE), descrita, pela primeira vez, em 1843 na França, foi registrada no continente americano, no Canadá em 1881, na Venezuela em 1960 e na Argentina em 1964². No Brasil, o primeiro registro da AIE foi firmado em 1968 por Dupont e colaboradores em animais da raça Puro Sangue Inglês (PSI) no antigo estado da Guanabara. $\mathrm{Na}$ época, o diagnóstico foi estabelecido com base em achados atribuídos à destruição de hemácias pela ação viral: presença de sideroleucócitos, desvios de valores de proteínas totais e frações em relação albumina/globulinas séricas, obtidos no perfil eletroforético, dosagem de proteínas séricas totais e frações seroprotéicas, bem como pela presença de depósitos de ferro em órgãos do sistema retículo endotelial ${ }^{3}$.

A AIE é uma doença cosmopolita, causada por um vírus do gênero Lentivirus da família Retroviridae, que acomete os equídeos independentemente de raça, idade e sexo ${ }^{4,5,6,7}$. É conhecida também como febre dos pântanos (swamp fever), pois a sua transmissão é facilitada nas áreas pantanosas onde a população de insetos hematófagos, vetores naturais, encontra condições favoráveis ao seu desenvolvimento.

O vírus da AIE é transmitido pela picada de tabanídeos (Tabanus sp.) e de moscas dos estábulos (Stomoxys calcitrans), que atuam como vetores mecânicos, pois o vírus não se replica nos insetos. No aparelho bucal das moscas o agente sobrevive apenas por curtos períodos de tempo e a transmissão é mais comum nas épocas mais quentes do ano, particularmente, nas regiões úmidas e pantanosas ${ }^{8}$.

A AIE apresenta distribuição mundial, com exceção do continente Antártico. Nas áreas endêmicas a sua prevalência pode atingir $70 \%$ dos animais adultos e, em geral, nas regiões com populações numerosas e permanentes dos insetos vetores os níveis de prevalência vão de moderados a altos. No Brasil, os estudos sorológicos realizados no período de 2002 a 2009 em vários estados brasileiros, como Pará, Minas Gerais, Mato Grosso do Sul, Goiás e Rio Grande do Sul, tem confirmadoa presença do vírus da AIE na população equina nacional ${ }^{8}$.

Carvalho Júnior ${ }^{9}$ relatou que de 1974 a 1993 a prevalência da AIE no Brasil foi de 11,51\% para região Norte, 3,36\% para o Nordeste, $8 \%$ no Centro-Oeste, $0,43 \%$ no Sudeste e $0,32 \%$ na região Sul. No período de 1999 a 2007, os registros do Ministério da Agricultura, Pecuária e Abastecimento (MAPA) referem que o número de focos de AIE confirmados no Brasil apresentou uma elevação, no entanto, a porcentagem de animais soropositivos apresentou discreta diminuição nacional ${ }^{8}$.

A prova padrão ouro, aceita internacionalmente para o estabelecimento do diagnóstico da AIE, é o teste de Imunodifusão em Gel de Agar (IDGA), prova qualitativa de grande praticidade, que apresenta $100 \%$ de especificidade e de 95 a 98,8\% de sensibilidade. Com este procedimento os anticorpos precipitantes específicos já podem ser detectados entre 14 a 45 dias da infecção $0^{3,4,6,10,11}$.

O presente trabalho teve como objetivo a análise comparativa das frequências de equídeos soropositivos para AIE em animais originários dos estados da Paraíba, Rio Grande do Norte e Ceará, submetidos ao controle oficial pelo MAPA durante o ano de 2010.

\section{Material e Método}

Em atendimento a Instrução Normativa no 45/2004 (Brasil 2004) $^{12}$, as colheitas de sangue foram efetuadas pelos Médicos Veterinários habilitados pelo MAPA. As amostras de sangue, colhidas por punção da veia jugular, em tubos com vácuo e capacidade para $8 \mathrm{~mL}$, foram acondicionadas em caixas isotérmicas, acompanhadas de requisição de exame e encaminhadas ao laboratório sob temperatura de refrigeração. 
A recepção e o processamento das amostras de sangue obedeceram a regulamentação estabelecida pela Portaria no 84 de 19 de Outubro de $1992^{13}$. Os exames foram realizados no Laboratório Veterinária Diagnósticos LTDA, localizado no município de Catolé do Rocha, estado da Paraíba.

Das 5.615 amostras de sangue examinadas, 1.926 foram procedentes de 99 municípios do estado da Paraíba, 2.679 amostras de 52 municípios do estado do Ceará e 1.010 de 58 municípios do estado do Rio Grande do Norte. Os estabelecimentos dos quais as amostras eram procedentes foram divididos em cinco categorias: Sociedade Hípica $(\mathrm{SH})$, Haras $(\mathrm{H})$, Fazenda Campestre (FC), Unidade Militar (UM) e Outros.

Para o diagnóstico sorológico de AIE, foi utilizado o teste de imunodifusão em gel de ágar (IDGA) ${ }^{14}$, utilizando-se o kit comercial produzido com o antígeno p26. O protocolo adotado seguiu as recomendações do fabricante.

A comparação das proporções de animais soropositivos por estado foi realizada com o emprego do teste de qui-quadrado ${ }^{15}$. A estimativa pontual e intervalar da odds ratio ${ }^{16}$ para a ocorrência de animais soropositivos para os estados, considerou como variável de referência o estado que apresentou a menor frequência de soropositividade. O nível de significância adotado foi de 5\% e as análises estatísticas foram efetuadas com o programa Epi Info versão 6.04 .

\section{Resultados}

Na tabela 1 são apresentados os resultados dos exames sorológicos para AIE pela IDGA de equinos dos três estados nordestinos estudados, com um total de 151 (2,69\%) animais soropositivos. As frequências de animais soropositivos por município são apresentadas na figura 1 . Houve diferença significativa na proporção de animais soropositivos entre os três estados $(\mathrm{p}=0,003)$. Os Estados da Paraíba e Ceará apresentaram maior risco de ocorrência de animais soropositivos quando comparados aos resultados obtidos em equinos originários do estado do Rio Grande do Norte.

A tabela 2 apresenta os resultados dos exames de AIE nos estados da Paraíba, Rio Grande do Norte e Ceará segundo os meses do ano. Na Paraíba, ocorreram casos de AIE em todos os meses do ano, com frequência variando de $0,58 \%$ em julho a $5,82 \%$ em junho; no Rio Grande Norte, em alguns meses, com variação de $0 \%$ em janeiro, fevereiro, junho e dezembro a 3,61\% em maio; e no Ceará, em todos os meses, variando de $1,10 \%$ em agosto a 7,29\% no mês de dezembro.

\section{Discussão}

No Brasil, em 1992, a prevalência de equinos infectados pelo vírus da AIE situava-se em torno de $3 \%{ }^{17}$. Contudo, a partir de 2007, os focos da doença no país apresentaram uma discreta diminuição, no entanto, a doença ainda está presente em todos os estados brasi-

Tabela 1 - Equinos submetidos ao teste de imunodifusão em gel de agar aplicado ao diagnóstico da Anemia Infecciosa Equina, segundo o estado de origem e a natureza dos resultados obtidos. Colheitas de sangue efetuadas em animais originários dos estados da Paraíba, Rio Grande do Norte e Ceará durante o ano de 2010

\begin{tabular}{|c|c|c|c|c|c|}
\hline Estado & $\begin{array}{c}\text { Animais } \\
\text { examinados }\end{array}$ & $\begin{array}{l}\text { Animais } \\
\text { positivos }\end{array}$ & $\%$ & $\begin{array}{c}\text { Odds ratio } \\
\text { (IC 95\%) }\end{array}$ & $\mathbf{p}$ \\
\hline Rio Grande do Norte & 1010 & 13 & 1,29 & 1 & $\ldots$ \\
\hline Paraíba & 1926 & 55 & 2,86 & $2,64(1,33-5,36)$ & 0,004 \\
\hline Ceará & 2679 & 83 & 3,10 & $2,87(1,48-5,71)$ & 0,001 \\
\hline Total & 5615 & 149 & 2,69 & $\ldots$ & $\ldots$ \\
\hline
\end{tabular}


$\operatorname{leiros}^{18}$. No presente trabalho, no ano de 2010, nos estados da Paraíba, Rio Grande do Norte e Ceará foram encontrados equinos positivos para AIE em vários municípios dos três estados trabalhados, distribuição apresentada na figura 1 , fato que apresenta grande relevância em relação ao controle do trânsito de animais

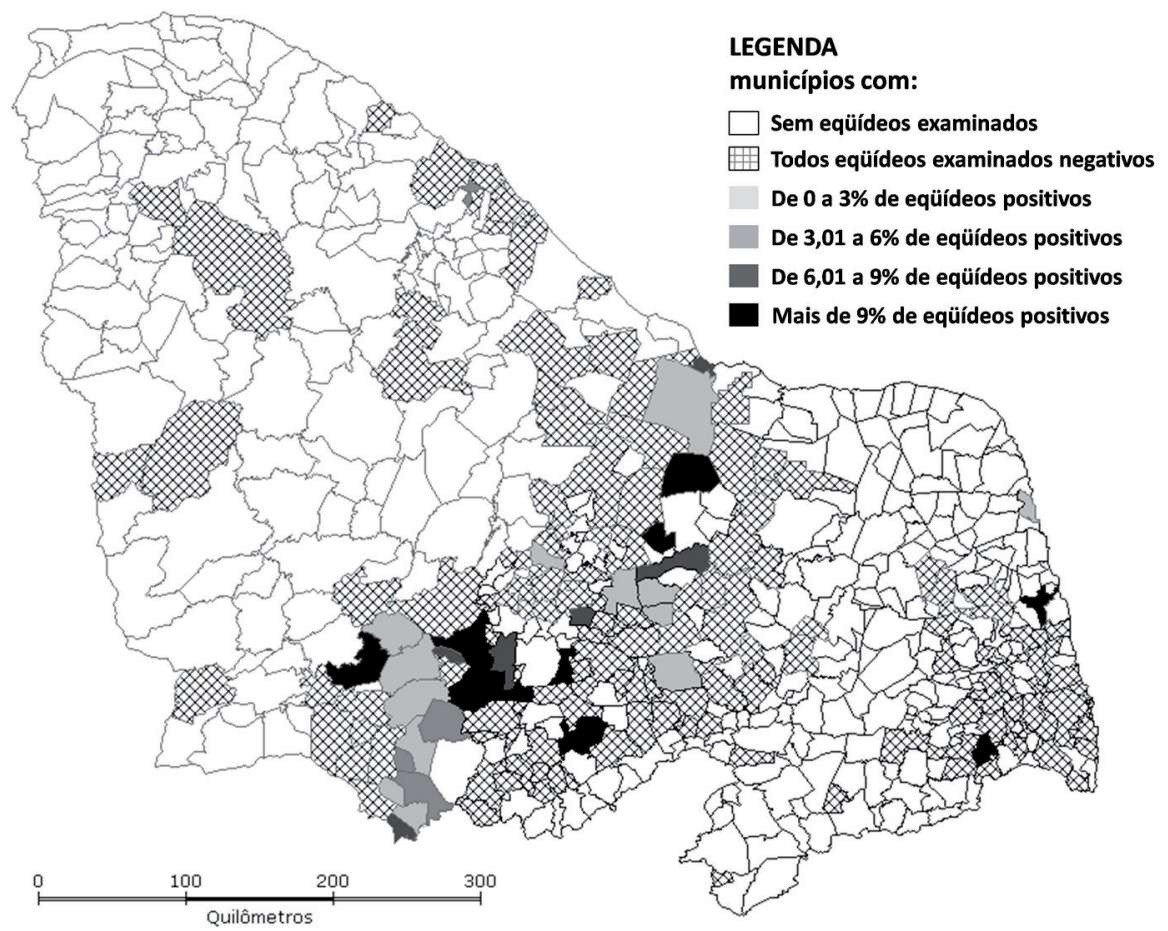

Figura 1 - Distribuição da frequência de equídeos soropositivos para Anemia Infecciosa Equina por município nosestados do Ceará, Rio Grande do Norte e Paraíba

Tabela 2 - Equinos submetidos ao teste de imunodifusão em gel de agar aplicado ao diagnóstico da Anemia Infecciosa Equina, segundo o estado de origem, o mês do ano e a natureza dos resultados obtidos. Colheitas de sangue efetuadas em animais originários dos Estados da Paraíba, Rio Grande do Norte e Ceará durante o ano de 2010

\begin{tabular}{lccccccccc}
\hline & \multicolumn{3}{c}{ Paraíba } & \multicolumn{4}{c}{ Rio Grande do Norte } & \multicolumn{5}{c}{ Ceará } \\
\cline { 2 - 8 } Mês & $\begin{array}{c}\text { Animais } \\
\text { examinados }\end{array}$ & Positivos & $\%$ & $\begin{array}{c}\text { Animais } \\
\text { examinados }\end{array}$ & Positivos & $\%$ & $\begin{array}{c}\text { Animais } \\
\text { examinados }\end{array}$ & Positivos & $\%$ \\
\hline Janeiro & 120 & 2 & 1,66 & 101 & 0 & 0 & 84 & 4 & 4,76 \\
Fevereiro & 81 & 2 & 2,47 & 38 & 0 & 0 & 82 & 3 & 3,66 \\
Março & 184 & 10 & 5,43 & 45 & 1 & 2,22 & 72 & 4 & 5,55 \\
Abril & 175 & 5 & 2,87 & 68 & 1 & 1,47 & 124 & 5 & 4,03 \\
Maio & 162 & 8 & 4,94 & 83 & 3 & 3,61 & 148 & 8 & 5,40 \\
Junho & 189 & 11 & 5,82 & 66 & 0 & 0 & 276 & 8 & 2,90 \\
Julho & 172 & 1 & 0,58 & 80 & 2 & 2,50 & 237 & 8 & 3,37 \\
Agosto & 184 & 4 & 2,17 & 92 & 1 & 1,09 & 547 & 6 & 1,10 \\
Setembro & 190 & 4 & 2,11 & 190 & 2 & 1,05 & 232 & 7 & 3,02 \\
Outubro & 182 & 3 & 1,65 & 72 & 1 & 1,39 & 275 & 6 & 2,18 \\
Novembro & 135 & 2 & 1,48 & 88 & 2 & 2,27 & 369 & 7 & 1,90 \\
Dezembro & 152 & 3 & 1,97 & 87 & 0 & 0 & 233 & 17 & 7,29 \\
Total & 1926 & 55 & 2,86 & 1010 & 13 & 1,29 & 2679 & 83 & 3,10 \\
\hline
\end{tabular}


entre municípios desses estados ou para outras regiões do nordeste e do país. A variação na frequência de soropositividade entre os municípios de origem pode ser atribuída a grande quantidade de eventos hípicos, como as vaquejadas em alguns municípios, bem como ao trânsito interestadual de animais, o que é evidenciado pela maior concentração de municípios com animais soropositivos nas divisas entre os três estados (Figura 1).

De fato, o vírus da AIE está presente em quase todos os países do continente Americano e, no ano de 2010, o maior número de focos foi registrado no Brasil ( $\mathrm{n}=2445)$, na Colômbia $(\mathrm{n}=2001)$ e no Paraguai ( $\mathrm{n}=545)$; houve também o registro de um menor número de focos no Equador $(\mathrm{n}=13)$ e no Peru $(\mathrm{n}=8)$. Nos outros países, apesar da doença estar presente, não foi disponibilizada a informação quantitativa do número de focos observados ${ }^{18}$. Na Colômbia, Sarmiento e Quijano-Pinzón ${ }^{19}$ referiram a prevalência de $8,06 \%$ e na Argentina, Jacobo et al. ${ }^{20}$ a de $15,2 \%$, valores superiores ao encontrado no presente trabalho $(2,66 \%)$ para os três estados analisados.

Dentre os poucos dados existentes sobre prevalência de AIE no Brasil, Carvalho Júnior ${ }^{9}$ referiu que entre 1974 e 1993 foram examinados 3.553 .626 equídeos dos quais 94.129 (2,65\%) foram positivos para AIE. As frequências por região foram: Norte 11,51\%; Nordeste 3,36\%; Centro-Oeste 8\%; Sudeste 0,43\%; e Sul 0,32\%. Especificamente na Paraíba e Rio Grande do Norte foram referidas prevalências de 1,5\% e 2,67\%, respectivamente ${ }^{21,22}$. Estes resultados são próximos aos valores encontrados no presente trabalho (2,66\%), revelando a inexistência de alteração significativa no perfil de ocorrência da doença nos períodos analisados.

\section{Referências}

1.INSTITUTO BRASILEIRO DE GEOGRAFIA E ESTATÍSTICA (IBGE). Censo Agropecuário. 2006. Disponível em: <http://www. ibge.gov.br/estadosat/perfil.php?sigla>. Acesso em: 5 out. 2011.
Dentre os três estados incluídos no presente trabalho, o estado do Ceará foi o que apresentou a maior frequência de equinos reatores para a AIE. Este fato pode ser explicado pela constatação de que o estado do Ceará é o detentor do maior rebanho de equídeos dentre os três estados investiga$\operatorname{dos}^{1}$, com 259.884 animais, e também por ser o que apresenta uma grande quantidade de eventos hípicos, como as vaquejadas ${ }^{4,23}$. Como na patogenia da AIE há muitos casos de animais que se comportam como portadores assintomáticos, ainda se observa uma grande resistência dos proprietários de equídeos para a implantação das ações destinadas ao controle da doença, pois os mesmos não estão suficientemente conscientes da necessidade da aplicação das condutas recomendadas pela legislação em vigor no país que incluem a eutanásia imediata dos animais e a interdição concomitante do trânsito de equídeos nas fazendas acometidas, até o completo saneamento do foco ${ }^{12}$.

\section{Conclusões}

$\mathrm{Na}$ amostra de conveniência empregada no presente trabalho, foi constatado que durante o ano de 2010 houve o registro de casos de anemia infecciosa equina nos três estados trabalhados: Rio Grande do Norte, Paraíba e Ceara. As frequências de ocorrência na Paraíba e Ceará foram mais elevadas que no Rio Grande do Norte. Na Paraíba e no Ceará, foram registrados casos de AIE em todos os meses do ano de 2010; no Rio Grande do Norte, não houve registro de casos de AIE nos meses de janeiro, fevereiro, junho e dezembro. Nos três estados trabalhados houve variação na distribuição da ocorrência da AIE segundo o município de origem dos animais.

2. MONTELARO, R. C.; BALL, J. M.; RUSHLOW, K. E. Equine retroviruses. In: LEVY, J. A. The retroviridae. New York: Plenum Press, 1993. v. 2, p. 257-360. 
3. MARTINS, M. F. Comparação entre os testes de IDGA (p26) e ELISA indireto (rgp90) no diagnóstico da Anemia Infecciosa Equina. 2004. 59 f. Dissertação (Mestrado) Universidade Federal de Minas Gerais, Belo Horizonte, Minas Gerais, 2004.

4. ISSEL, C. J.; COGGINS, L. Equine infectious anemia: current knowledge. Journal of the American Veterinary Medical Association, v. 174, n. 7, p. 727-733, 1979.

5. COOK, S. J.; COOK, R. F.; MONTELARO, R. C.; ISSEL, J. C. Differential responses of Equus caballus and Equus asinus to infection with two pathogenic strains of equine infectious anemia virus. Veterinary Microbiology, v. 79, n. 2, p. 93-109, 2001

6. ALMEIDA, V. M. A.; GONÇALVES, V. S. P.; MARTINS, M. F.; HADDAD, J. P. A.; DIAS, R. A.; LEITE, R. C.; REIS, J. K. P. Anemia infecciosa eqüina: prevalência em eqüídeos de serviço em Minas Gerais. Arquivo Brasileiro de Medicina Veterinária e Zootecnia, v. 58, n. 2, p. 141-148, 2006.

7.CUENCA, J. C.; PRADO, E. S. Prevalencia de anemia infecciosa equina en el municipio de Santa Clara, Cuba. REDVET. Revista Eletrónica de Veterinaria, v. 12, n. 1, 2011 Disponível em: <http://www.veterinaria.org/revistas/redvet/ n010111/011105.pdf>. Acesso em: 12 abr. 2012.

8. FRANCO, M. M. J.; PAES, A. C. Anemia infecciosa eqüina. Veterinária e Zootecnia, v. 18, n. 2, p. 197-207, 2011.

9. CARVALHO JÚNIOR, O. M. Anemia infecciosa eqüina: "AIDS" do cavalo. Revista de Educação Continuada, v. 1, p. 16-23, 1998.

10.COGGINS, L.; NORCROSS, N. L. Immuno-diffusion reaction in equine infectious anemia. Cornell Veterinarian, v. 60 , n. 2 , p. $330-335,1970$.

11.COGGINS, L.; NORCROSS, N. L.; NUSBAUM, R. Diagnosis of equine infectious anemia by immunodifusion test. American Journal of Veterinary Research, v. 33, n. 1, p. 11-17, 1972 .

12. BRASIL. Ministério da Agricultura, Pecuária e Abastecimento. Secretaria de Defesa Agropecuária. Instrução normativa no 45 , de 15 de junho de 2004. Aprovar as Normas para a Prevenção e o Controle da Anemia Infecciosa Equina. Ministério da Agricultura, Pecuária e Abastecimento. Diário Oficial da União,Brasília, DF, 07 jul. 2004. Seção 1, p. 7.

13.BRASIL. Portaria no 84 de 19 de Outubro de 1992. Anexo I: Técnica de imunodifusão em gel de ágar para diagnóstico de anemia infecciosa eqüina. Ministério da Agricultura, Pecuária e Abastecimento. Diário Oficial da União, Brasília, DF, 22 out. 1992. Seção 1, p. 14874.
14.WORLD ORGANIZATION FOR ANIMAL HEALTH (OIE). Equine infectious anaemia.Manual of Standards for Diagnostic Tests and Vaccines for Terrestrial Animals. 2008. Disponível em: <http://www.oie.int/eng/normes/mmanual>. Acesso em: 27 abr. 2012.

15.ZAR, J. H. Biostatistical analysis. $4^{\text {th }}$ ed. New Jersey: Prentice Hall, 1999. 663 p.

16.THRUSFIELD, M. Veterinary epidemiology. $3^{\text {rd }}$ ed. Oxford: Blackwell Science, 2007. 624 p.

17.REBELATTO, M. C.; OLIVEIRA, C.; WEIBLEN, R.; SILVA, S. F; OLIVEIRA, L. S. S. Serological diagnosis of equine infectious anemia virus infection in the central region of the Rio Grande do Sul state. Ciência Rural, v. 22, n. 2, p. 191-196, 1992.

18. WORLD ORGANIZATION FOR ANIMAL HEALTH. OIE. Terrestrial animal health code. 2011. Disponível em: <http:// www.oie.int>. Acesso em: 10 out. 2011.

19.SARMIENTO, P.; QUIJANO-PINZÓN, M. Prevalencia del virus de la anemia infecciosa equina (AIE) en dos poblaciones de caballos de trabajo de los departamentos del Chocó y La Guajira. Revista de la Facultad de Ciencias, v. 10, n. 2, p. 55 60, 2005.

20.JACOBO, R. A.; STORANI, C. A.; CIPOLINI, M. F; STAMATTI, G. M.; MIRANDA, A. O.; CARDOZO, R. O.; MARTÍNEZ, D. E.; DANSEY, M. B. Seroprevalencia de Anemia Infecciosa Equina em La Provincia de Corrientes, período 2001-2002. Comunicaciones Cientificas y Tecnológicas v. 1, 2003. Disponível em: <http://www.unne.edu.ar/Web/ cyt/cyt/2003/comunicaciones/04-Veterinarias/V-001.pdf $>$. Acesso em: 12 abr. 2012.

21.SILVA, M. H. Soroprevalência da Anemia infecciosa equina em equídeos no Estado da Paraíba. 2007. 28 f. Trabalho de Conclusão de Curso (Especialização) -Universidade de Santo Amaro, Recife, Pernambuco, 2007.

22. CAVALCANTE, P. H. Risco de transmissão do vírus da anemia infecciosa equina por eqüídeos errantes no Município de Mossoró, RN. 2009. 45 f. Dissertação (Mestrado) - Universidade Federal Rural do Semi-Árido, Mossoró, Rio Grande do Norte, 2009.

23. SELLON, D. C. Equine infectious anemia. Veterinary Clinics of North America: Equine Practice, v. 9, n. 2, p. 321-336, 1993.

24. CAMPBELL, C. T.; NUSBAUM, S. R. Epidemiologic importance of interstate transport of equids infected with equine infectious anemia vírus. Journal of the American Veterinary Medical Association, v. 198, n. 8, p. 1332-1333, 1991. 